Revista de Derecho

\title{
Responsabilidad del empleador por mobbing horizontal
}

\section{Employer's responsibility for horizontal mobbing}

\author{
José Antonio Burneo Burneo \\ Juez de lo Contencioso Administrativo \\ Quito, Ecuador \\ jburneo_1959@yahoo.es \\ ORCID: 0000-0002-5267-3894 \\ José Antonio Burneo Carrera \\ Abogado en libre ejercicio \\ Ecuador \\ jaburneo_94@outlook.es \\ ORCID: 0000-0003-4787-8200
}

DOI: https://doi.org/10.32719/26312484.2021.35.3

Fecha de recepción: 17 de mayo de 2020

Fecha de aceptación: 22 de septiembre de 2020 


\section{RESUMEN}

Actualmente, en el campo del Derecho del trabajo, el mobbing laboral es una de las situaciones más perjudiciales de las relaciones de trabajo, cuyas repercusiones afectan tanto al trabajador como al empleador. Primero, porque entorpece los procesos internos dentro de la organización, lo que a su vez repercute en los resultados de la empresa. Segundo, debido a que el empleador es quien se beneficia de la fuerza de trabajo de sus empleados, es lógico que tenga la obligación de brindarles medios e instalaciones seguras a los trabajadores para la prestación lícita y personal de sus servicios. Esta obligación es la carga del empleador de brindar un ambiente sano y propicio para las relaciones laborales. En caso de que el empleador infrinja esta obligación, objetiva e indisponible, deberá hacer frente a las condenas pecuniarias que le correspondan, a pesar de que en el caso del mobbing horizontal no tenga ni siquiera conocimiento de los hechos de acoso realizado entre sus trabajadores. Este breve escrito buscará clarificar en qué circunstancias cabe la responsabilidad del empleador en casos de mobbing horizontal, por su posición de garante de los derechos de los trabajadores, y cómo la normativa sanciona su omisión por no ofrecer un ambiente sano de trabajo.

PalABras Clave: trabajo, empleador, responsabilidad, hostigamiento, mobbing, indemnización.

\section{ABSTRACT}

Working place is the scenario of a many situation where the worker's personality is affected. Labor mobbing is one of the most damaging situations in work relationships. Because it hinders the internal processes within the organization, so that poor communication and the psychological damage that bullying produces are affected by the company's results. Also, because the employer is the one who benefits from the workforce of its employees, so it is logical that they have the obligation to provide them with secure means and facilities for the lawful and personal provision of their services. Generically, we call this obligation the employer's burden of providing a healthy and conducive environment for labor relations. If the employer infringes this liability, objective and unavailable, he must face the pecuniary sentences that correspond to him, even though in the case of horizontal mobbing, he is not even aware of the acts of harassment carried out among his workers. This brief document will seek to clarify in what circumstances the employer's responsibility falls in cases of horizontal mobbing or workplace harassment, due to its position as guarantor of workers' rights.

KEYWORDS: work, employer, liability, harassment, mobbing, compensation. 


\section{INTRODUCCIÓN}

¿- s responsable el empleador por actos de acoso cometidos entre trabajadores? L Para responder esta interrogante han sido planteados diferentes elementos de análisis. En primer lugar, serán revisados el concepto y alcances del compliance laboral, desde el punto de la inicial definición de compliance hasta la tendencia actual de separarlo de la materia penal; de modo que abarque también al campo del Derecho laboral. En línea con ello, examinaremos también el fundamento de los códigos de ética, los cuales son medios de autorregulación que facultan a las empresas a normar aspectos que superan a los mínimos legales, con la intención de sumar eficiencia y valor a las organizaciones, esencialmente, por medio del aseguramiento de un ambiente sano de trabajo.

Por otro lado, ya insertos en el tema central de la investigación, serán revisados varios aspectos del mobbing, el cual es la agresión psicológica o moral hacia un trabajador para poner en peligro su estabilidad laboral. Además, serán expuestos diferentes motivos por los cuales creemos que es necesario tomar muy en cuenta al mobbing, desde su prevención hasta su manejo correctivo prudente, para evitar la responsabilidad del empleador. Seguidamente, ahondaremos en el breve y particular estudio del mobbing horizontal, el cual es el acoso u hostigamiento de un trabajador hacia otro de su misma jerarquía organizacional. Para explicar el tema en cuestión, serán tomados en cuenta diferentes causas que van desde el mero celo profesional hasta la competencia excesiva por puestos de trabajo específicos o ascensos.

Con base en los conceptos descritos, será estudiada la posición garantista que toma la normativa laboral en nuestro país, ya que le otorga al empleador una calidad de garante de los derechos de los trabajadores a su cargo, específicamente dentro del ambiente de trabajo. Por el ostento de dicha calidad, el empleador tiene la obligación objetiva de garantizar no solo un ambiente sano a los trabajadores, sino también debidos procesos de compliance dentro de las organizaciones que denoten una activa participación con respecto a la prevención del mobbing o, en su defecto, a la canalización de denuncias sobre este tipo de hechos abusivos y tan perjudiciales a nivel psicológico para los trabajadores. Con todo este planteamiento, será expuesta la idea de una responsabilidad objetiva del empleador, tras la cual, después de demostrarse su responsabilidad, puede llegar a ser condenado a un tipo de indemnización específica pero no tan evidente, expuesta dentro del Código del Trabajo. Para llegar a esta conclusión, utilizaremos un método lógico-deductivo, partiendo de las premisas que serán explicadas a lo largo del escrito; enfatizando los aspectos legales aplicables al mobbing horizontal en el Ecuador. 


\section{COMPLIANCE LABORAL Y LOS CÓDIGOS DE ÉTICA}

\section{EL LABOR COMPLIANCE}

El término compliance ha sido estereotipado al ámbito de prevención y manejo del incumplimiento penal. Inicialmente porque, desde sus raíces anglosajonas, no es posible dejar de lado el móvil que le dio origen, la perpetuación de delitos penales por intermedio de personas jurídicas a mediados del siglo pasado. ${ }^{1}$ De igual forma, la rama de prevención de incumplimiento penal podría decirse que tiene efectos "visibles" o evidentes, pues, tras la perpetuación de un delito a través de la organización, la penalidad puede ser la disolución de la persona jurídica que la sustenta y que fue utilizada para el ilícito; sin perjuicio de que la responsabilidad penal también pueda alcanzar a sus directores. ${ }^{2}$ Por esto es que se le ha entregado cierto protagonismo al campo penal en el compliance, sin olvidar que es tan solo un elemento que compone el amplio y variado terreno del manejo de riesgos de incumplimiento en el campo empresarial; menciónese: prevención de lavado de activos, societario, laboral, etc.

La disposición, organización, regulación y control de las herramientas empresariales - organizativas - de normativización de protocolos de prevención de incumplimiento normativo no solo es una tendencia sino una necesidad para las empresas. ${ }^{3}$ Primero porque su compleja estructura va a ser directamente proporcional a los riesgos en que estuviere expuesto. Segundo, debido a que la inclinación legislativa en nuestro país ha sido creciente a agigantados pasos, por lo que: a mayor normativa, mayor será el ejercicio que deben realizar los agentes regulados (esto incluye a las empresas en su calidad de empleadoras). No obstante, a pesar de dicha necesidad, la cultura de autorregulación ha sido pobremente desarrollada, lo que evidencia que las empresas se limitan a cumplir con la normativa emitida por los agentes externos de control - es decir las instituciones estatales - que poco o nada conocen sobre la realidad de una empresa del sector privado. Así pues, los protocolos de prevención de incumplimiento, especialmente las autoimpuestas, deben ser una prioridad en las empresas. ${ }^{4}$

1. Raúl Saccani y Gustavo Morales Oliver, Tratado de compliance (Buenos Aires: La Ley, 2018), $345-52$.

2. Véase Roxin, Derecho Penal Parte General (Barcelona, 1992), 205-9. En sus escritos, Roxin diferencia claramente la imputación penal entre directores o administradoras y la persona jurídica, tendencia que se ha hecho parte la normativa penal ecuatoriana en el artículo 280 del Código Orgánico Integral Penal, donde el delito de cohecho diferencia las sanciones pertinentes para uno y otro.

3. Saccani y Morales Oliver, Tratado de compliance, 345-52.

4. Raúl Rojas, Compliance laboral (Madrid, 2017), 5-9. 
El compliance laboral puede ser conceptualizado como aquella acción corporativa de la gestión de riesgos de incumplimiento de la norma laboral. ${ }^{5}$ En el sistema jurídico ecuatoriano, esta práctica de gestión es derivada en el mandato legal dispuesto en el artículo 33 de la Constitución de la República del Ecuador (C.R.E), ${ }^{6}$ en el sentido de que es obligación del Estado garantizar a las personas trabajadoras el pleno respeto de su dignidad humana y sus derechos adquiridos; de modo que el Estado, en su posición de garante superior, emite normas no disponibles que los empleadores tienen que acatar para cumplir con dichas garantías constitucionales. ${ }^{7}$

El labor compliance - compliance aplicado al Derecho del trabajo- tiene como objeto y campo de estudio la gestión de tres riesgos básicos: Por un lado, los riesgos de sanciones legales o nulidad de actos que representen decisiones empresariales sobre normas del trabajo; o, lo que es lo mismo, el cumplimiento del Orden Público Laboral. En otro sentido, los riesgos de sanciones económicas por multas administrativas que pueden repercutir en el desempeño de la empresa/empleador. Finalmente, el riesgo moral al cual están expuestos los empleadores (esencialmente empresas), que en el campo laboral tiene especial atención porque, dependiendo del giro del negocio, las empresas son lo que sus empleados transmiten, de modo que, si estos no tienen cubiertos y garantizados sus derechos como trabajadores, van a comunicar una imagen negativa de la empresa. ${ }^{8}$

Si bien la tendencia del compliance ha sido la de superar la estereotipación del campo penal, esta no ha sido suficiente para permitir un avance considerable en otras ramas del derecho, como lo es el labor compliance. En ese sentido, existe una absurda creencia de que el buen empleador es quien tiene a sus trabajadores en la formalidad — o sea en blanco-, lo cual es únicamente una de sus más elementales obligaciones. Ahora, el considerable crecimiento de la normativa laboral, sostenida en los últimos años, provoca que los empleadores agreguen esfuerzos para verificar el cumplimiento de la normativa laboral obligatoria y además que identifiquen espacios donde la ley les permite ejercer cierto campo de disposición y manejo facultativo para emprender proyectos de autorregulación, tendientes a mejorar las relaciones entre trabajadores $\mathrm{y}$, por otro lado, entre trabajadores y su empleador. ${ }^{9}$

5. Ibíd.

6. Ecuador, Constitución de la República del Ecuador, Registro Oficial 449, 20 de octubre de 2008, art. 33.

7. Es posible concatenar dicha obligación del Estado con el deber fundamental de este de cumplir y hacer cumplir la Constitución, las leyes y los tratados internacionales; lo que incluye las normas de trabajo.

8. César Montoya Agudelo y Martín Boyero Saavedra, "El recurso humano como elemento fundamental para la gestión de calidad y la competitividad organizacional", Revista científica Visión del Futuro 20, n. ${ }^{\circ}$ 2 (2016): 1-23.

9. Javier Ricardo Dolorier Torres, “Orden Público Económico, Orden Público Laboral, y límites a la autonomía colectiva", Revista Themis, 1 (2015): 205-21. 
En el Ecuador no existe norma alguna que exija o regule programas de prevención de incumplimiento o de labor compliance; peor aún la figura del labor compliance officer. De modo que el camino está propuesto por normas supranacionales de softlaw. Las normas ISO son un conjunto de normas, reglas y principios que tienen como objeto la cobertura del control y gestión de calidad de las organizaciones..$^{10}$ Estas normas son emitidas por la Organización Internacional de Normalización (ISO por sus siglas en inglés) que es la institución internacional encargada de la homogeneización de normas de carácter organizacional para fomentar la estandarización global en el campo industrial y comercial.

En tal sentido, para fines del labor compliance, podría ser aplicable la norma ISO196000 sobre sistemas de gestión de compliance, que es una norma genérica, de modo que sean las propias organizaciones que van a aplicarlas las encargadas a hacer un ejercicio de individualización según las necesidades de sus respectivas estructuras. Lo que se busca con la implementación del labor compliance no solo es evitar el incumplimiento normativo, sino también la creación de buenas prácticas laborales, como podrían ser los códigos de ética entre empleados, que es una buena herramienta para combatir el mobbing, ${ }_{11}^{11}$ objeto de esta investigación.

\section{IMPORTANCIA DE LOS CÓDIGOS DE ÉTICA}

Idealmente, en línea con lo dicho por Hermosa, toda empresa debe tener implementados códigos de conducta y ética del personal que sea congruente con su programa de riesgos laborales para que los trabajadores moderen y coadyuven su comportamiento con los objetivos propuestos por la organización empleadora. ${ }^{12}$ Legalmente no hay obligación de implementar códigos de ética y comportamiento en el estricto sentido de la palabra. No obstante, la figura del Reglamento Interno de Trabajo (RIT) tiene bastantes similitudes. El R.I.T. se encuentra regulado en el artículo 64 del Código del Trabajo, si bien este artículo se refiere a fábricas también incluye a establecimientos de trabajo colectivo, por lo que podría aplicarse a una variedad de organizaciones donde exista interacción continua y simultánea entre varios trabajadores.

Los códigos de ética o de comportamiento para los trabajadores y empleadores son un pilar fundamental del labor compliance. En principio porque permite reglamen-

10. Saccani y Morales Oliver, Tratado de compliance, 347.

11. Yolanda Cobo Saiz, "El mobbing. Hacer visible, lo invisible" (Cantabria: Universidad de Cantabria, 2013), 123-44.

12. Eduardo Hermosa Torres, "El mobbing o acoso laboral, pautas para su tratamiento en el Ecuador" (tesis de maestría, Universidad Andina Simón Bolívar, Sede Ecuador, 2017), 41-52. 
tar el comportamiento de los prestadores de servicios (trabajadores) para disminuir riesgos laborales. Además, porque apertura de canales de denuncias formalizados en donde puedan identificarse de mejor manera los comportamientos anómalos dentro de la empresa. Así pues, es asimilable que el código de ética es esencial para el labor compliance porque sirve de marco regulatorio de las relaciones laborales, más allá de la normativa imperativa, y, a su vez, asegura su correcta divulgación y sociabilización entre los trabajadores, ya que representa un pliego de normas condensadas, eliminando la informalidad y la dispersión; algo que sucede generalmente en la normativa legal emanada por las instituciones públicas.

\section{EL MOBBING}

Los códigos de ética que proveen normativa de obligatorio cumplimiento entre trabajadores son de vital importancia en la prevención del mobbing. En sí, abarca, de manera general, la prevención del acoso, impulsa la salud ocupacional, el buen trato y la comunicación efectiva en la organización. ${ }^{13}$ La relación de los empleados en el ambiente de trabajo es bastante compleja y es obligación del empleador entregar un ambiente sano y propicio para la prestación de los servicios lícitos y personales de los trabajadores; esto según el número 8 del art. 45 del Código de Trabajo.

La alta competencia en el mercado laboral que supone el proceso de globalización ha repercutido en la frecuencia en que los trabajadores incurren en actividades perjudiciales para el clima laboral. ${ }^{14}$ Entre esas actividades aparece el mobbing, un anglicanismo que proviene de la locución inglesa to mob, que puede traducirse como la acción de acosar u hostigar. ${ }^{15}$ En el intento por sintetizar la definición del mobbing, es posible concebirlo como acoso moral, acoso laboral u hostigamiento psicológico. ${ }^{16}$

Según la Real Academia de la Lengua Española, acosar implica "apremiar de forma constante o insistente a alguien con molestias o requerimientos"; por su parte, hostigar es la molestia o burla hacia alguien de forma insistente. ${ }^{17} \mathrm{Si}$ bien están relacionados, estos dos términos no son sinónimos. No obstante, son englobados dentro

13. Raúl Rojas, Compliance laboral, 5-9.

14. Mara Maricela Trujillo Flores, María de la Luz Valderrábanos Almegua y René Hernández Mendoza, "Mobbing: historia, causas, efectos y propuesta de un modelo para las organizaciones mexicanas", Revista de Ciencias Administrativas y Sociales, 1 (2007): 71-92.

15. María del Carmen Vidal Casero, "El mobbing en el trabajo: su problemática", Bioeticacs.org, 2013.

16. Adriana Ávila Cadavid, Valentina Bernal Toro y Laura Alzate, “¿Cuáles son las causas y consecuencias del acoso laboral o mobbing?", Revista electrónica Psyconex 8, n. 13 (2016): 1-10.

17. Marco Antonio Espinoza y Doris Gallegos, "Discriminación laboral en Ecuador", Revista Espacios 39, n. ${ }^{\circ}$ 23 (2018): 32-48. 
de la figura del mobbing, debido a que se trata, en el campo del derecho, de un concepto indeterminado. Así pues, será encuadrable en cada caso particular, en razón de las circunstancias y normativa respectiva, la terminología a aplicarse; sin olvidar que el Código del Trabajo, tácitamente, incluye en su art. 42 num. 36 el hostigamiento dentro de la figura general del acoso laboral, siendo obligación del empleador implementar programas para prevenirlo o, en su defecto, sancionarlo.

El primero en utilizar, en el campo laboral, la figura del mobbing fue el psicólogo alemán Heinz Leymann, quien formuló el concepto del acoso laboral como: "situación en que una o más personas son objeto de violencia psicológica de forma sistemática y recurrente, durante un tiempo prolongado, por lo cual se ve mermada su estabilidad psicológica y reputacional; afectando sus labores debido a la desmotivación laboral". En ese sentido, puede sintetizarse la figura en cuestión, en suma de la figura de la hostilidad laboral, como la existencia de una comunicación deficiente y un comportamiento abusivo y perjudicial para un trabajador en el ámbito del trabajo. ${ }^{18}$

En la normativa ecuatoriana encontramos la definición del acoso laboral o mobbing en el artículo innumerado siguiente al artículo 46 del Código del Trabajo, el cual menciona:

Debe entenderse por acoso laboral todo comportamiento atentatorio a la dignidad de la persona, ejercido de forma reiterada, y potencialmente lesivo, cometido en el lugar de trabajo o en cualquier momento en contra de una de las partes de la relación laboral o entre trabajadores, que tenga como resultado para la persona afectada su menoscabo, maltrato, humillación, o bien que amenace o perjudique su situación laboral.

Con base en esa conceptualización, debemos destacar algunos elementos del mobbing, a parte del evidente acoso u hostigamiento descrito en líneas anteriores: ${ }^{19}$

- Alta frecuencia: Para que se compruebe la existencia del mobbing, tiene que ser reiterado, puesto que los actos aislados, a ojos de la normativa ecuatoriana, no son considerados como acoso laboral.

18. Véase: Heinz Leymann, Mobbing: la persécution au travail (París: Seuil, 1996). En su obra, el doctor Leymann, si bien menciona el ámbito del trabajo, esto incluye el ámbito espacial, es decir, el establecimiento donde efectivamente se trabaja, así como también las relaciones posteriores o derivadas de ello; de modo que puede existir acoso laboral aun fuera del horario del trabajo y en lugares distintos que, inicialmente, serían de un interés ajeno al empleador. El punto importante es la acción de un compañero de trabajo hacia otro; las demás son variables no determinantes para identificar el mobbing, teniendo enorme importancia para su estima el perjuicio no para verificar su existencia.

19. Eduardo Caamaño Rojo, "La noción de acoso moral laboral o 'mobbing' y su reconocimiento por la jurisprudencia en Chile", Revista de Derecho de la Pontificia Universidad Católica de Valparaíso, 37 (2011): 215-40. 
- Por tiempo prolongado: A más de ser reiterado, los actos tendientes a desmoralizar a un trabajador deben ser sostenidos en el tiempo. Si bien no existe un tiempo exacto para imputarse el acoso, consideramos que debería ser por un lapso mayor a noventa días, considerando que, si bien no es obligatorio, la gran mayoría de empleadores hacen parte de su derecho al período de prueba que el Código del Trabajo determina en su artículo 15, según el cual las partes pueden terminar la relación laboral sin indemnización alguna, por lo que se entiende que no cumplió sus expectativas. En tal sentido, el período de prueba, a más de ser muy corto, no brinda elementos razonables para sustentar actos de acoso laboral.

Recordemos que todo trabajo, en mayor o menor medida, implica un cierto nivel de estrés para el empleado. De modo que, para que se configure el mobbing y disparar la protección, multa e indemnizaciones correspondientes que provee la ley, deberá existir una alteración considerable en los niveles de estrés del trabajador, capaz de afectar su estado psicológico y repercutir en el desempeño de su trabajo. ${ }^{20}$

\section{OBJeto DEL MOBbING}

El acoso laboral no puede analizarse ni verificarse de forma dispersa, tiene que ser dirigido. Esto quiere decir que las actuaciones del acosador deben ser tendientes a obtener un resultado en específico de una persona o grupo de personas. De modo que el objeto del acosador debe ser claramente identificable, con respecto a la persona a agredir, el perjuicio esperado y el resultado beneficioso que representará para el acosador. ${ }^{21}$ Un ejemplo de ello, y bastante típico en el mobbing, es cuando un compañero de trabajo desestabiliza emocionalmente a otro que está compitiendo por un ascenso, con la intención de que este último renuncie y se desvincule de la empresa. ${ }^{22}$

Para cumplir con su objetivo, el acosador busca la clandestinidad. Esto no obsta que exista un acoso público para denigrar o descalificar el trabajo de alguien, lo que es más verificable en el Bossing. ${ }^{23}$ En el mobbing horizontal, por su parte, la clandestinidad es clave para el éxito del plan perjudicial del acosador, porque el empleador ignora o desconoce la existencia de dichas situaciones, dificultando un ejercicio de

20. Ibíd.

21. José Carvajal Orozco y Carlos Dávila Londoño, "Mobbing o acoso laboral. Revisión del tema en Colombia”, Cuadernos de Administración Universidad del Valle 29, n. ${ }^{\circ} 9$ (2013): 92-106.

22. Adriana Marcela Manrique, "Acoso Laboral (Mobbing): Riesgo Psicosocial Emergente Invisible", Revista Interamericana de Psicología Ocupacional 38, n. ${ }^{\circ}$ (2019): 127-9.

23. Bossing es aquel acoso en el cual el perpetuador tiene un grado jerárquico distinto. Para más sobre el tema véase: Jorge Enrique Romero-Pérez, "Mobbing Laboral: acoso moral, psicológico", Revista de Ciencias Jurídicas $1, \mathrm{n} .^{\circ} 111$ (2006): 131-62. 
previsión o corrección al comportamiento abusivo del mobbing; muy aparte de que existan ya planes de prevención del acoso laboral. ${ }^{24}$

Aparte del objetivo general y direccionado del acosador, que es la desestabilización psicológica del trabajador, tiene además objetivos específicos y metódicos que hacen parte del proyecto dañoso. En primer orden, es perseguida la marginación social del afectado o potencial acosado; en el sentido de que esto favorecerá al desarmamiento de la unificación y cooperación entre trabajadores, o sea que el empleado se sienta desprotegido. ${ }^{25}$ Por otro lado, el acoso debe ir direccionado a la deficiencia en la prestación de los servicios lícitos y personales del trabajador acosado, de forma tal que no sean cubiertas satisfactoriamente sus obligaciones laborales. Finalmente, y en palabras de Leymann, la inestabilidad psicológica que evidencia un malestar de carácter patológico. ${ }^{26}$

Concluimos que el mobbing es un acto dañoso y eminentemente doloso. ${ }^{27}$ Fernández Madrid defiende la idea de no solo la existencia de una intención evidente del acosador por causar un perjuicio en el compañero de trabajo, sino que también supone actos preparatorios de planeación y organización; de modo tal que el acosador se esfuerza por dañar. ${ }^{28} \mathrm{El}$ dolo, según el art. 29 del Código Civil, consiste en la intención positiva de irrogar injuria a la persona o propiedad de otro. Es indiscutible entonces que el mobbing es un acto doloso, pero en caso de controversias laborales esa intención positiva de afectar la estabilidad moral y psicológica de un trabajador deberá probarse, ya que, en ningún caso, según el art. 1475, ibíd., el dolo se presume.

\section{EL MOBBING HORIZONTAL}

Explicado lo que implica el ejercicio del mobbing, bajo el entendimiento de acoso laboral en el trabajo, es prudente acotar los puntos de estudio al objeto de este análisis; el mobbing horizontal. Esta modalidad de acoso laboral trata de aquel perjuicio o inestabilidad psicológica que realiza un trabajador a otro de su misma jerarquía organiza-

24. Ramón Gimeno, "La presión laboral tendenciosa" (tesis doctoral, Universidad de Girona, 2004).

25. Marie-France Hirigoyen, El acoso moral en el trabajo: distinguir lo verdadero de lo falso (Barcelona, 2001), 23-34.

26. Según Leymann, la inestabilidad psicológica puede ser de carácter pasajero o sostenido por un tiempo prolongado, independientemente de si continúa prestando servicios dentro de la empresa. Inferimos entonces que, en caso de demostrarse responsabilidad del empleador por acoso psicológico, el juez ha de ordenar que además este costee la terapia para el afectado, en modalidad de reparación no pecuniaria.

27. Miguel Barón Duque, Lourdes Munduate Jaca y María José Blanco Barea, "La espiral del Mobbing", Papeles del Psicólogo 23, n. ${ }^{\circ} 84$ (2003): 71-82.

28. Gimeno, "La presión laboral tendenciosa". 
cional..$^{29}$ Es decir, es aquella situación de agresividad u hostigamiento realizado por un compañero del ambiente de trabajo donde no existe superposición oficial por puestos. De tal forma, el abusador obtiene un poder de facto producido por un comportamiento amenazador o perturbador hacia la víctima. ${ }^{30}$

En vista de que no existe una jerarquización formal de poder por puestos de trabajo superiores entre los participantes de este tipo de mobbing, es inferirle que el acosado, en la mayoría de las ocasiones, sea una persona con un mejor perfil profesional que el acosador; lo cual pone en peligro el ascenso de este último dentro de la organización. En razón de eso, el acosador decide deshacerse de esa amenaza laboral mediante una afectación silenciosa pero altamente perjudicial, el acoso moral. ${ }^{31} \mathrm{El}$ hecho de que dichos participantes tengan un rango profesional igual, o parecido, dentro de la organización no determina un menor grado de lesión por actos del acoso; pues es totalmente independiente. ${ }^{32}$ De tal modo, en línea con Cobo, la intensidad, alcance, periodicidad y continuidad de los actos de acoso serán las variables determinantes para medir un perjuicio a nivel laboral, mas no la posición que ocupan los perpetuadores. ${ }^{33}$

Este tipo de mobbing suele estar relacionado con el elevado nivel de competitividad en las organizaciones, ${ }^{34}$ porque en determinadas profesiones o industrias, el reconocimiento público del trabajo hace parte de un sistema desviado que sobrepasa los tradicionales méritos laborales. ${ }^{35}$ Por otro lado, el hostigamiento laboral también es producto de bajos niveles de compañerismo en la organización, lo que a su vez deriva de la competitividad desmesurada entre trabajadores. Así pues, la sana idea de la competencia se ve distorsionada por ambientes hostiles de trabajo donde el comportamiento del empleador, mediante programas de ética organizacional, es esencial para elevar o disminuir los riesgos de acoso laboral entre trabajadores.

29. Romero-Pérez, "Mobbing Laboral: Acoso moral, psicológico", 141.

30. Cobo Saiz, "El mobbing. Hacer visible, lo invisible", 14.

31. Gimeno, "La presión laboral tendenciosa".

32. Armando Mario Rojas, "El acoso o 'mobbing' laboral", Revista de Derecho Universidad del Norte, 24 (2005): 230-4

33. Cobo Saiz, "El mobbing. Hacer visible, lo invisible", 14.

34. Mara Maricela Trujillo Flores, María de la Luz Valderrabano Almegua y René Hernández Mendoza, en su artículo: "Mobbing: historia, causas, efectos y propuesta de un modelo para las organizaciones mexicanas", revelan que un estudio demostró que las industrias más propensas al acoso entre trabajadores son aquellas donde los salarios son bajos y que los ingresos gruesos de los trabajadores son las comisiones por volúmenes de ventas. Entonces no es descabellado concluir que la exagerada carga competitiva que impone el empleador, más que ser beneficiosa, produce índices de estrés exagerados, desencadenando una pérdida del espíritu de compañerismo entre los trabajadores.

35. Ibíd. 


\section{RESPONSABILIDAD DEL EMPLEADOR POR MOBBING HORIZONTAL}

Para comprender en qué medida es responsable un empleador por actos de acoso entre sus trabajadores de la misma jerarquía, donde este desconoce los diferentes actos hostiles debido a que son realizados de forma clandestina, es necesario verificar dos puntos centrales: por un lado, su calidad de garante de derechos de sus trabajadores, por el principio de subordinación. El otro punto es que la ley le otorga la calidad de causal para terminar con el contrato de trabajo, donde nuestro interés será aquella situación en la que el trabajador termine con la relación laboral y le sea imputado al empleador el pago de las respectivas indemnizaciones que la propia ley ordena.

Con respecto al primer punto, el trabajador es el sujeto protegido por el Derecho del trabajo. Por ende, la normativa de Orden Público Laboral debe ir encaminada hacia su tutela como grupo débil en las relaciones laborales. ${ }^{36}$ Esta protección le otorga la facultad al trabajador de ejercer acciones en caso de violación a sus derechos. En ese sentido, tras un daño ocasionado por una situación de acoso laboral que tuvo como resultado una grave deficiencia en la estabilidad psicológica de la víctima, esta podrá presentar las acciones, ya sean judiciales o administrativas, que crea pertinentes en contra de su empleador de forma directa. ${ }^{37}$ Ahora, en casos de plantearse dicha acción no será necesario dirigirla exclusivamente al representante legal de la organización empleadora, sino, por el contrario, podrá ser direccionada a quien el trabajador considere como empleador, sin importar si lo desconoce.

En la misma línea de lo antedicho, desde la visión del trabajador, y desde donde parte el Derecho del trabajo, el empleador no es únicamente quien figura en el rol de pagos del sueldo, también abarca a quienes ejerzan su representación. El Código del Trabajo ha sido claro en ese sentido, de modo que en el artículo 36 menciona que los representantes del empleador serán todos aquellos quienes, a nombre de él, ejerzan funciones de dirección y administración. Además, vale la pena agregar lo que la jurisprudencia ha decidido sobre ello: en los fallos de triple reiteración II-A, II-B y II-C de la Gaceta Judicial mayo-agosto de 1998, página 3241 es aclarado que no es obligación del trabajador conocer quién ejerce la representación legal de la empresa donde presta sus labores. Por todo ello es deducible que, en casos de violación a sus derechos por acoso laboral, el trabajador afectado podrá accionar no solo contra el

36. Juan Carlos Fernández Madrid, Tratado práctico del derecho del trabajo (Buenos Aires: La Ley, 1990), 55-61.

37. Caamaño Rojo y Ugarte, "El acoso laboral: tutela y prueba de la lesión de los derechos fundamentales", 69-71. 
representante legal de la organización, sino también a quienes ejerzan funciones de dirección, que bien podrían ser sus jefes superiores.

Según el artículo 44 del mencionado cuerpo legal, el empleador tiene la prohibición expresa de cometer actos de acoso laboral, o de autorizarlos, ya sea por acción, lo que supondría una posición activa en el mobbing, o por omisión, es decir no haber tomado los recaudos necesarios para evitar dichos actos de acoso. Con respecto a la omisión, si bien se entendería que el empleador desconoce o ignora la existencia de una situación de mobbing horizontal por los motivos explicados, su obligación es de carácter objetivo, porque supone un deber de cuidado, lo que en materia penal es llamado como posición de garante. De tal forma, es posible concluir que el empleador es responsable en mobbing horizontal debido a su posición de garante ante las relaciones laborales acaecidas en su establecimiento y de los derechos de los trabajadores que laboran para él, más que todo porque es el empleador quien se beneficia de dicha fuerza de trabajo; por lo que debe ofrecer las condiciones idóneas para que el derecho constitucional al trabajo sea ejercido satisfactoriamente, en beneficio de ambas partes de la relación laboral.

Con respecto al segundo punto central de la responsabilidad del empleador por acoso laboral horizontal debemos resaltar que esta es considerada como una causal legal para la terminación del contrato de trabajo. El acoso laboral, descrito en el artículo innumerado siguiente al artículo 46 del Código del Trabajo, es causal de visto bueno, tanto en favor del trabajador como del empleador. Siendo nuestro interés la causal de visto bueno descrita en el art. 173 núm. 4 ibíd., la cual faculta al trabajador a dar por terminado el contrato de trabajo en caso de sufrir acoso laboral, cometido o permitido por acción u omisión por el empleador o sus representantes legales. De tal forma, el mobbing horizontal que sufre el trabajador es encuadrable dentro de este artículo, posibilitándolo a darse por despedido tras la concesión del mencionado visto bueno por parte del Inspector del Trabajo; todo eso tiene como resultado el derecho a exigir el pago de las indemnizaciones descritas en el artículo 189 ibídem.

Procesalmente, un empleador que ha sido desahuciado, previo visto bueno, tras comprobarse su responsabilidad por omisión en casos de mobbing horizontal, será obligado a cancelar las indemnizaciones aplicables al despido ineficaz, descrito en el art. 195.3 en su tercer inciso del Código del Trabajo, correspondiente a un año de salario, según el último salario percibido. ${ }^{38}$ De más está decir que las implicaciones de no manejar un control diligente del ambiente de trabajo son bastante severas; no obstante, pueden ser pensadas también como incentivos negativos que alienten la creación

38. La bonificación por desahucio por acoso laboral es completamente indistinta a las indemnizaciones correspondientes por despido intempestivo, siendo obligación del empleador también cancelarlas. 
e implementación de programas de labor compliance tendientes a la erradicación del acoso laboral.

Muy aparte de si es o no beneficiosa una normativa tan severa y estricta con respecto al empleador, lo que es ineludible de precisar es la existencia de una responsabilidad objetiva. Como consecuencia de ello, en caso de que el trabajador active la acción administrativa del visto bueno para dar por terminado el contrato de trabajo por la causal descrita en líneas pasadas, este solo deberá presentar ante el Inspector del Trabajo indicios fundados de haber sufrido acoso laboral. En tal escenario será el empleador el encargado de desvirtuar esas acusaciones mediante la justificación de un comportamiento diligente ante un riesgo potencial de mobbing entre trabajadores de la misma jerarquía organizacional, que es bastante probable que desconozca. Como defensa ante una acusación administrativa de este tipo, el empleador deberá demostrar que ha aplicado los debidos actos preventivos, canales de denuncia y medidas correctivas necesarias para evitar el acoso laboral dentro de su establecimiento; ${ }^{39} \mathrm{o}$, lo que es lo mismo, demostrar que ha ejercido un prudente programa de labor compliance.

Con respecto a los indicios que debe brindar el trabajador para activar las investigaciones de mobbing, entendemos que la norma canaliza estas denuncias de forma tan viable y abierta debido al principio de protección administrativa en favor del trabajador, dispuesto en el art. 5 del Código del Trabajo, en concordancia con el principio indubio pro-operario, consagrado en el artículo 9 del mismo cuerpo legal.

La exigencia al trabajador de tan solo indicios de haber sufrido acoso laboral revierte la carga de la prueba, ahora en manos del empleador, quien deberá demostrar los puntos expuestos en el párrafo anterior; muy aparte de la existencia o no del acoso por parte de otro trabajador. En vista de su calidad de garante de los derechos de los trabajadores, los esfuerzos del empleador serán direccionados a verificar que este puso a disposición de los trabajadores los canales de denuncia pertinentes para evitar que el acoso prosiga; de tal forma podrá justificar que no es encuadrable dentro de la figura de la omisión, aunque todo dependerá de la decisión del Inspector del Trabajo. No está por demás decir que este tipo de argumentos es únicamente aplicable en el mobbing horizontal, donde el empleador tiene una posición pasiva, de modo que la naturaleza de la responsabilidad por infracciones directas por el empleador, como el Bossing, nada tienen que ver con ese tipo de razonamiento.

39. Hermosa Torres, "El mobbing o acoso laboral, pautas para su tratamiento en el Ecuador", 25-36. 


\section{ACOSO LABORAL EN EL ESCENARIO ECUATORIANO}

A partir de la reforma del Código del Trabajo, en el mes de noviembre de 2017, donde fue incluida la figura del acoso laboral en la legislación laboral ecuatoriana, fueron presentadas un número considerable de denuncias por esta situación. Así, en el año 2018 fueron presentadas, a lo largo de las 32 dependencias regionales que posee el Ministerio del Trabajo a nivel nacional, un total de 359 denuncias por acoso, sin tener una distinción exacta de cuántas fueron por mobbing horizontal. ${ }^{40}$

Dentro del año siguiente, la tendencia de la presentación de denuncias continuó con un patrón ascendente. No obstante, a nivel judicial no existe una cifra exacta que especifique las causas que se han sustanciado por este tipo de acoso; esencialmente porque la mayoría de las controversias suelen disiparse a nivel administrativo, donde es el Inspector del Trabajo el encargado de dirimir la controversia, específicamente otorgando o negando el visto bueno, según fue explicado en párrafos pasados.

\section{CONCLUSIONES}

- El empleador deberá entregar un ambiente de trabajo propicio y sano para que se lleve a cabo la prestación de los servicios lícitos y personales de los trabajadores. Al hacerlo, es materializado el principio legal dispuestos en el artículo 66 de la Constitución de la República del Ecuador sobre el derecho al libre desarrollo de la personalidad de los trabajadores, el cual, si es debidamente garantizado en su lugar de trabajo, reduce el riesgo de que su estabilidad psicológica se vea afectada por un colaborador; pues, en caso de que así sea, el empleador será responsable por ello, debido a su calidad de garante.

- Los Reglamentos Internos de Trabajo que implementen los empleadores deberán contener códigos de ética funcionales, basados en el labor compliance, que protejan los derechos de los trabajadores y además los intereses del empleador, tras el establecimiento de una relación laboral armónica y saludable. De modo que las normas autoimpuestas que elija aplicar el empleador deberán ser acordes también al principio de responsabilidad por actos propios, el cual obliga a este a cumplir con estándares de control de cumplimiento mayores a los exigidos por la ley, pero creados por sí mismo y a su medida, para otorgar un cierto grado de seguridad a los trabajadores con respecto al respeto de sus derechos.

40. Jonathan Machado, "En 20 meses se han reportado 518 denuncias por acoso laboral”, Primicias.ec, 28 de agosto de 2019. 
- Los programas de canalización de denuncias en las organizaciones es un medio eficaz para poner en alerta a los empleadores sobre hechos de mobbing horizontal, debido a que el acosador va a buscar la clandestinidad para cumplir con su objetivo. En el escenario de que el empleador sea alarmado de estos hechos, podrá aplicar medios correctivos que podrán evitar el cargo de indemnizaciones, pero sin que esto represente una disminución en su nivel de responsabilidad; pues siempre el empleador tendrá la posición de garante de los derechos del trabajador y, por ende, una obligación objetiva con respecto a ellos.

- En casos de mobbing horizontal que sean denunciados administrativamente a través del proceso de investigación ante el Inspector del Trabajo, el trabajador afectado únicamente deberá proveer indicios de la existencia del acoso laboral; mientras que el empleador deberá probar su inexistencia o, en su defecto, que, a pesar de haber existido, no incumplió omisivamente su deber de garante. En caso de que la terminación del contrato de trabajo por parte del trabajador, previo visto bueno, sea basado en la causal cuarta del artículo 173 del Código de Trabajo, o sea por acoso laboral, el empleador deberá indemnizar al trabajador afectado con el valor correspondiente a un año de salario, sin perjuicio de las indemnizaciones por despido intempestivo y por desahucio, porque su obligación, como se reiteró, es objetiva en caso de mobbing horizontal. Como peculiaridad a este planteamiento, resaltamos que el trabajador acosador no se hace responsable por el mobbing en el campo laboral, muy aparte de que el empleador pueda también dar por terminada la relación laboral, por lo que el trabajador afectado deberá accionar ante su acosador por la vía civil y bajo las reglas particulares del daño moral.

\section{BIBLIOGRAFÍA}

Ackerman, Mario. "El trabajo, los trabajadores y el derecho del trabajo". Revista TST, Brasília 73, n. ${ }^{\circ} 3$ (2007): 50-80.

Ávila Cadavid, Adriana, Valentina Bernal Toro y Laura Alzate. “¿Cuáles son las causas y consecuencias del acoso laboral o mobbing?". Revista electrónica Psyconex 8, n. 13 (2016): 1-10. https://revistas.udea.edu.co/index.php/Psyconex/article/view/326991/20784214.

Barón Duque, Miguel, Lourdes Munduate Jaca y María Blanco Barea. "La espiral del Mobbing". Papeles del Psicólogo 23, n. 84 (2003): 71-82.

BDO España. "Protocolos laborales: Radiografía de su implementación en España". Madrid, 2018.

Caamaño Rojo, Eduardo. "La noción de acoso moral laboral o 'mobbing' y su reconocimiento por la jurisprudencia en Chile". Revista de Derecho de la Pontificia Universidad Católica de Valparaíso, 37 (2011): 215-40. https://scielo.conicyt.cl/pdf/rdpucv/n37/a05.pdf. 
Caamaño Rojo, Eduardo, y José Luis Ugarte. "El acoso laboral: tutela y prueba de la lesión de los derechos fundamentales". Revista Ius et Praxis 20, n. ${ }^{\circ} 1$ (2014): 67-90. https://scielo. conicyt.cl/pdf/iusetp/v20n1/art04.pdf.

Carvajal Orozco, José, y Carlos Dávila Londoño. "Mobbing o acoso laboral. Revisión del tema en Colombia”. Cuadernos de Administración Universidad del Valle 29, n. 49 (enerojunio 2013): 92-106.

Cobo Saiz, Yolanda. "El mobbing. Hacer visible, lo invisible". Cantabria: Universidad de Cantabria, 2013, 67-83.

Dolorier Torres, Javier Ricardo. “Orden Público Económico, Orden Público Laboral, y límites a la autonomía colectiva”. Revista Themis (2015): 205-18.

Ecuador. Código del Trabajo. Registro Oficial 167, Suplemento, 16 de diciembre de 2005.

Ecuador. Constitución de la República del Ecuador. Registro Oficial 449, 20 de octubre de 2008.

Espinoza, Marco Antonio, y Doris Gallegos. "Discriminación laboral en Ecuador". Revista Espacios 39, n. ${ }^{\circ} 23$ (2018): 32-48.

Fernández Madrid, Juan Carlos. Tratado práctico del derecho del trabajo. Buenos Aires: La Ley, 1990.

García Amado, Juan Antonio. "Responsabilidad jurídica". Revista en Cultura de la Legalidad, n. ${ }^{\circ} 1$ (2011): 125-32.

Gimeno, Ramón. "La presión laboral tendenciosa”. Tesis doctoral, Universidad de Girona, 2004.

González Trijueque, David, y Sabino Delgado Marina. “Acoso psicológico en el lugar de trabajo, Burnout y psicopatología. Un estudio piloto con el BSI y el MBI”. Boletín de psicología, n. ${ }^{\circ} 94$ (noviembre 2008): 47-58.

Hermosa Torres, Eduardo. "El mobbing o acoso laboral, pautas para su tratamiento en el Ecuador”. Tesis de maestría, Universidad Andina Simón Bolívar, Sede Ecuador, 2017.

Hirigoyen, Marie-France. El acoso moral en el trabajo: distinguir lo verdadero de lo falso. Barcelona, 2001.

Hopenhayin, Martín. Repensar el trabajo: historia, profusión y perspectivas de un concepto. Buenos Aires: Editorial Norma, 2001.

Jiménez-Bonilla, Denisse, y Edgar Jiménez-Bonilla. "Clima laboral y su incidencia en la satisfacción de los trabajadores de una empresa de consumo masivo". Revista Ciencia UNEMI 9, n. ${ }^{\circ} 18$ (junio 2016): 26-34.

Lanas Medina, Elisa. "La prueba en demandas laborales por discriminación". FORO: Revista de Derecho, n. ${ }^{\circ} 14$ (2010): 69-91.

Leymann, Heinz. Mobbing: la persécution au travail. París: Seuil, 1996.

Lucas Marín, Antonio. Sociología de la empresa. Madrid: Ibérico Europea de Ediciones, 1992.

Lugo Garfias, María Elena. Acoso laboral “mobbing”. Ciudad de México: Comisión Nacional de los Derechos Humanos, 2017. 
Machado, Jonathan. "En 20 meses se han reportado 518 denuncias por acoso laboral”. Primicias.ec, 28 de agosto de 2019. Nota completa en https://www.primicias.ec/noticias/sociedad/acoso-laboral-trabajadores-empleadores/.

Manrique, Adriana Marcela. “Acoso Laboral (Mobbing): Riesgo Psicosocial Emergente Invisible”. Revista Interamericana de Psicología Ocupacional 38, n. ${ }^{\circ} 2$ (2019): 127-9.

Montoya Agudelo, César, y Martín Boyero Saavedra. "El recurso humano como elemento fundamental para la gestión de calidad y la competitividad organizacional". Revista científica Visión del Futuro 20, n. ${ }^{\circ} 2$ (2016): 1-23.

Pasten de Ishihara, Gloria. "Derecho del trabajo: su relación e integración con los derechos humanos, la economía y la sociología”. Revista de derecho del trabajo (2003): 110-69.

Peralta, María Claudia. "El acoso laboral — mobbing - perspectiva psicológica”. Revista de Estudios Sociales 1, n. ${ }^{\circ} 18$ (2004): 111-22.

Piñel y Zabala, Iñaki, y Araceli Oñate Cantero. "La incidencia del mobbing o acoso psicológico en el trabajo en España". LAN HARREMANAK (2002): 35-62.

Rojas, Armando Mario. “El acoso o 'mobbing' laboral”. Revista de Derecho Universidad del Norte, 24 (2005): 230-48. http://rcientificas.uninorte.edu.co/index.php/derecho/article/ viewFile/2560/1678.

Rojas, Raúl, Compliance laboral. Madrid, 2017.

Romero-Pérez, Jorge Enrique. "Mobbing Laboral: Acoso moral, psicológico". Revista de Ciencias Jurídicas 1, n. ${ }^{\circ} 111$ (2006): 131-62.

Saccani, Raúl, y Gustavo Morales Oliver. Tratado de compliance. Buenos Aires: La Ley, 2018.

Trujillo Flores, Mara Maricela, María de la Luz Valderrabano Almegua y René Hernández Mendoza. "Mobbing: historia, causas, efectos y propuesta de un modelo para las organizaciones mexicanas". Revista de Ciencias Administrativas y Sociales (2007): 71-92.

Trujillo, Julio César. Derecho del Trabajo. Quito: Pontificia Universidad Católica del Ecuador, 1986.

Unión Sindical de Madrid Región de CCOO. “Acoso psicológico en el trabajo (mobbing). Los efectos de la nueva organización”. Madrid, 2002.

Vidal Casero, María del Carmen. "El mobbing en el trabajo: su problemática". Bioeticacs.org, 2013. 